This is an electronic version of an article published in:

Journal of Early Childhood Research 5 (3), 219-243 (2007)

The journal is available online at:

http://ecr.sagepub.com/cgi/content/abstract/5/3/219

Intergenerational learning between children and grandparents in East London

Charmian Kenner, Mahera Ruby, Eve Gregory, John Jessel and Tahera Arju

Department of Educational Studies

Goldsmiths, University of London 


\section{Intergenerational learning between children and grandparents in East London}

This study investigates the learning exchange between 3-6 year old children and their grandparents, in Sylheti/Bengali-speaking families of Bangladeshi origin and monolingual English-speaking families living in East London. The following concepts from sociocultural theory are applied to this new area of intergenerational learning: 'scaffolding', 'synergy' leading to mutual benefits for the young child and their caregiver, 'syncretising' of knowledge from different sources, 'funds of knowledge' within communities, and the transmission of knowledge or 'prolepsis' between generations. Methods include an initial survey at a primary school to establish the range of learning activities taking place at home between grandparents and children, followed by case studies of nine families through interviews, videorecording and scrapbooks. Qualitative analysis of the data reveals how learning interactions are coconstructed by children and grandparents within a relationship of mutuality in which touch is a particularly significant mode of communication. The intergenerational exchange develops concepts and skills that complement children's school learning, and involves cultural continuity as well as change.

\section{Keywords}

grandparents, intergenerational learning, Bengali, mutuality, touch, cultural knowledge 


\section{Introduction}

This paper reports on a study of intergenerational learning between children and grandparents, aiming to enhance understanding of the sociocultural aspects of learning in an area where little research has previously been conducted. By analysing the ways in which each generation contributes to the knowledge of the other, the paper identifies the characteristics and the results of such learning exchanges. It also suggests how initiatives in lifelong learning and family learning could draw upon and support the role of grandparents as carers.

The study looks closely at the intergenerational learning exchange between young children attending a primary school in Tower Hamlets, East London, and their grandparents. The school has a culturally mixed intake, with the two main linguistic groups being Sylheti/Bengali-speaking* children from families of Bangladeshi origin, and monolingual English-speaking children, some from mixed-race families. The project worked with families of both these groups, in order to gain understanding of learning interactions in different cultural and linguistic contexts. The focus was on children in the early years (from nursery to Year 1, ages three to six), because very young children have the most evident need of help and care from their grandparents. An investigation of this age group gives particularly rich insights into the potential for intergenerational learning.

Key concepts from sociocultural theory relevant to young children's learning experiences with other family members include guidance through 'scaffolding' provided by caregivers (Wood, Bruner \& Ross 1976), the 'syncretising' of knowledge and experience from different sources (Gregory and Williams, 2000), 'synergy' 
leading to mutual benefits for the young child and others involved (Gregory, 2001), 'funds of knowledge' within communities (Moll et al, 1992; González, Moll and Amanti, 2005), and the transmission of knowledge or 'prolepsis' between generations (Cole 1996). The study applies these concepts to interactions between children and grandparents, in order to highlight the characteristics of this area of intergenerational learning.

\section{The importance of intergenerational learning}

Intergenerational studies has recently emerged as an academic discipline (Newman et al, 1997; Granville and Ellis, 1999; Van, 2004) including research on grandparenthood (Smith and Drew, 2002; Attias-Donfut and Segalen, 2002). However, there have been no studies investigating grandparents' role in children's learning. Such studies are also lacking within the field of early childhood research. Although the importance of family interaction in children's learning has been widely recognised in the US (Heath, 1983), the UK (Hannon, 1995), Australia (Cairney and Ruge, 1998) and New Zealand (McNaughton, 1995), the spotlight has tended to focus on parents rather than other family members.

More recently, this focus has widened to include interaction between siblings (Rashid and Gregory, 1997; Volk with de Acosta, 2004). An ethnographic study by Gregory and Williams (2000) in Tower Hamlets highlighted the importance of siblings in bilingual learning, and benefits for both older and younger siblings have been identified (Gregory, 2001). Research on parents and children has also begun to conceptualise the interaction as a mutual exchange, for example in Duran's study (2001) of US Hispanic parents learning from their children when helping with English 
homework. The issue of grandparents' interaction with children now needs complementary development. This investigation is particularly timely since grandparents are increasingly involved in the care of young children; for example, one-fifth of grandparents in Britain now provide childcare to support working parents (Dench \& Ogg, 2002), and in cases of kinship care (when parents are unable to look after their children) grandparents often become the major or only source of support (Clark \& Cairns, 2001; Richards, 2001).

\section{A sociocultural approach to intergenerational learning}

Sociocultural theories of learning (Tharp \& Gallimore 1988, Pollard with Filer, 1996), based on the work of Vygotsky (1978), have proved particularly fruitful in exploring young children's learning experiences within the family. Vygotskyan theory explains how a child first encounters new concepts through interaction with others in her cultural community, and subsequently integrates these ideas into her individual understanding. Thus 'an interpersonal process is transformed into an intrapersonal one' (Vygotsky, 1978: 57). As Cole and Scribner point out, for Vygotsky 'the mechanism of individual developmental change is rooted in society and culture' (Cole and Scribner, 1978: 7).

Educationalists have focused on how this exchange of ideas between child and caregiver takes place. Wood, Bruner and Ross (1976) proposed that parental tutoring in the pre-school years involves guidance through 'scaffolding', a form of cognitive support later described by Maybin, Mercer and Stierer as 'help which will enable a learner to accomplish a task which they would not have been quite able to manage on their own' (Maybin, Mercer and Stierer (1992: 188). However, Rogoff points out from 
observations in different cultural contexts that 'children and their social partners, particularly their caregivers, are interdependent rather than independent' (Rogoff, 1990: 193). She therefore suggests that children's 'apprenticeship' to others is an active role, in which 'guided participation is jointly managed by children and their companions in ways that facilitate children's growing skills' (Rogoff, 1990: viii).

This co-construction of learning can involve a 'synergy' between the participants, as shown by Gregory (2001) in a study of bilingual siblings 'playing school' at home. Gregory defines synergy as 'a unique reciprocity whereby siblings act as adjuvants in each other's learning' (Gregory, 2001: 309); although the older sibling takes the official role of teacher, the process of interaction with the younger child requires the re-formulation of concepts and thus triggers additional learning for both.

How might grandparents' interaction with children compare with that of other family members? At first sight it seems as though the grandparent-child dynamic would be similar to that of parents and children, rather than the more equal roles found in sibling interactions. However, this is an assumption requiring further examination. Additionally, learner-teacher relationships can shift and become more reciprocal when families move to a new country and children become fluent in the dominant language more rapidly than adults, as found by Kenner (2005).

Turning to the kinds of knowledge gained by young children through learning with family members, sociocultural theory again has a particular contribution to make. Culture is seen as understandings shared between members of a community, jointly created through social practice. In all societies, and particularly in contexts of 
migration, cultural knowledge is dynamic and continually changing. This involves the 'syncretising' of knowledge and experience from different sources, 'a creative process in which people reinvent culture as they draw on diverse resources' (Gregory, Long and Volk, 2004: 5).

Just as young children take an active part in the processes of learning, so they also coconstruct the ideas that result. A social semiotic perspective, as developed by Kress (1997) in his examination of young children's writing, further illuminates how this happens. Kress shows how children produce signs that, whilst shaped by their cultural world, carry their own interpretation as meaning-makers; 'children, like adults, never copy....we transform the stuff which is around us - usually in entirely minute and barely noticeable ways' (Kress, 1997: 96).

When children and grandparents learn together, the relationship may offer particular scope for 'transformation' of ideas and for 'syncretising' cultural information. Grandparents are likely to be important resources for the 'funds of knowledge' held within communities, defined as 'historically accumulated and culturally developed bodies of knowledge and skills essential for household or individual functioning and well-being' (Moll et al, 1992: 133). At the same time, children may also have new competences that their grandparents would like to access, such as how to operate technology that is unfamiliar to the older generation. The child-grandparent relationship when a family moves to a new country may especially show this dynamic, due to children taking the lead in developing knowledge of the new language and new cultural tools. 
These changing cultural contexts provide fascinating territory within which to examine how 'prolepsis' (Cole, 1996) functions between the two generations. Cole developed the idea of 'prolepsis' to explain how a parent brings memories from their own past into current interactions with their child, and how these memories both expand and limit the child's experience as the adult imagines what the future for the child might be. Grandparents will also be bringing such ideas to bear on their relationship with a grandchild, and the creative tensions arising as concepts are jointly developed through intergenerational learning have yet to be explored.

\section{The study}

The research project discussed here set out to investigate intergenerational learning in families from different cultural backgrounds whose young children all attended the same East London primary school. As mentioned earlier, the families involved were Sylheti/Bengali-speaking families settled in London, and monolingual Englishspeaking (some of mixed-race). In order to examine the theoretical issues discussed above, we decided to collect data on informal learning events taking place at home between young children and grandparents, both in activities where older people would be more likely to provide support (such as storytelling, cooking or gardening) and in the newer areas of information and communication technology where leadership might switch to children. In both cases we anticipated an exchange of knowledge and skills, and the study would explore the dynamics involved.

Our research questions were as follows: 
1) In what ways do grandparents and children take the lead in the learning interactions?

2) In what ways are the learning interactions co-constructed by the participants?

3) What kinds of knowledge are exchanged between the younger and older learners?

\section{Methods}

A survey was first conducted at the primary school on learning at home between grandparents and children, followed by ethnographic case studies of nine families through interviews, videorecording of learning events, and scrapbooks.

\section{Survey}

To gain an overview of learning activities taking place at home between grandparents and children, a questionnaire was distributed to families with children in nursery, Reception and Year 1 (ages 3-6) thought by the school to have contact with grandparents. The questions concerned the amount of contact with grandparents, the range of activities taken part in together, and the languages used in the course of these activities. 20 families answered, 17 Sylheti/Bengali-speaking and 3 monolingual English-speaking.

Nine families agreed to take part in an in-depth examination of the intergenerational exchange. Six families were Sylheti/Bengali-speaking and three monolingual Englishspeaking. From these families, eleven children were involved in our research, six bilingual in Sylheti/Bengali and English (Sahil, Sumayah, Anayet, Anayah, Amani, Abida) and five monolingual (siblings Lizzie and Sam, and Oscar and Cosmo, whose families were of UK white origin, and Steven whose maternal grandparents were from 
Guyana). Six were boys and five were girls. Four were in Year 1, four in Reception and three in nursery.

\section{Interviews}

Grandparents were asked about their overall role in grandchildren's learning, and particular aspects of learning for both child and grandparent taking place in the different activities carried out together. Children were also interviewed about what they and their grandparents learned from each other.

\section{Video-recording}

Families were asked to suggest typical activities that children and grandparents enjoyed doing together. For each family, two activities were video-recorded, each lasting around 15 minutes. We requested that one of these should be a computer activity, and in cases where the family did not possess a computer, the researchers took a laptop to homes. This enabled grandparents and children to explore a new learning tool in a familiar environment.

\section{Scrapbooks}

To gain additional data from the families' perspective, scrapbooks were provided to record activities grandparents and children enjoyed together. Families placed a variety of material in these scrapbooks, including photographs, children's drawings and writing, and artefacts ranging from brochures of places visited to a small bag of lentils used in cooking or fragments of birds' eggs and leaves collected from the garden. 


\section{Range of activities and languages found in the survey}

The questionnaire offered a list of possible activities in which grandparents might engage with their grandchildren. The list was drawn up by the research team, and included ideas emerging from consultation with members of the local Bangladeshi community. Grandparents selected from these options and added any activities not mentioned. The results (for 20 families, including 21 children altogether) are shown in Figure 1.

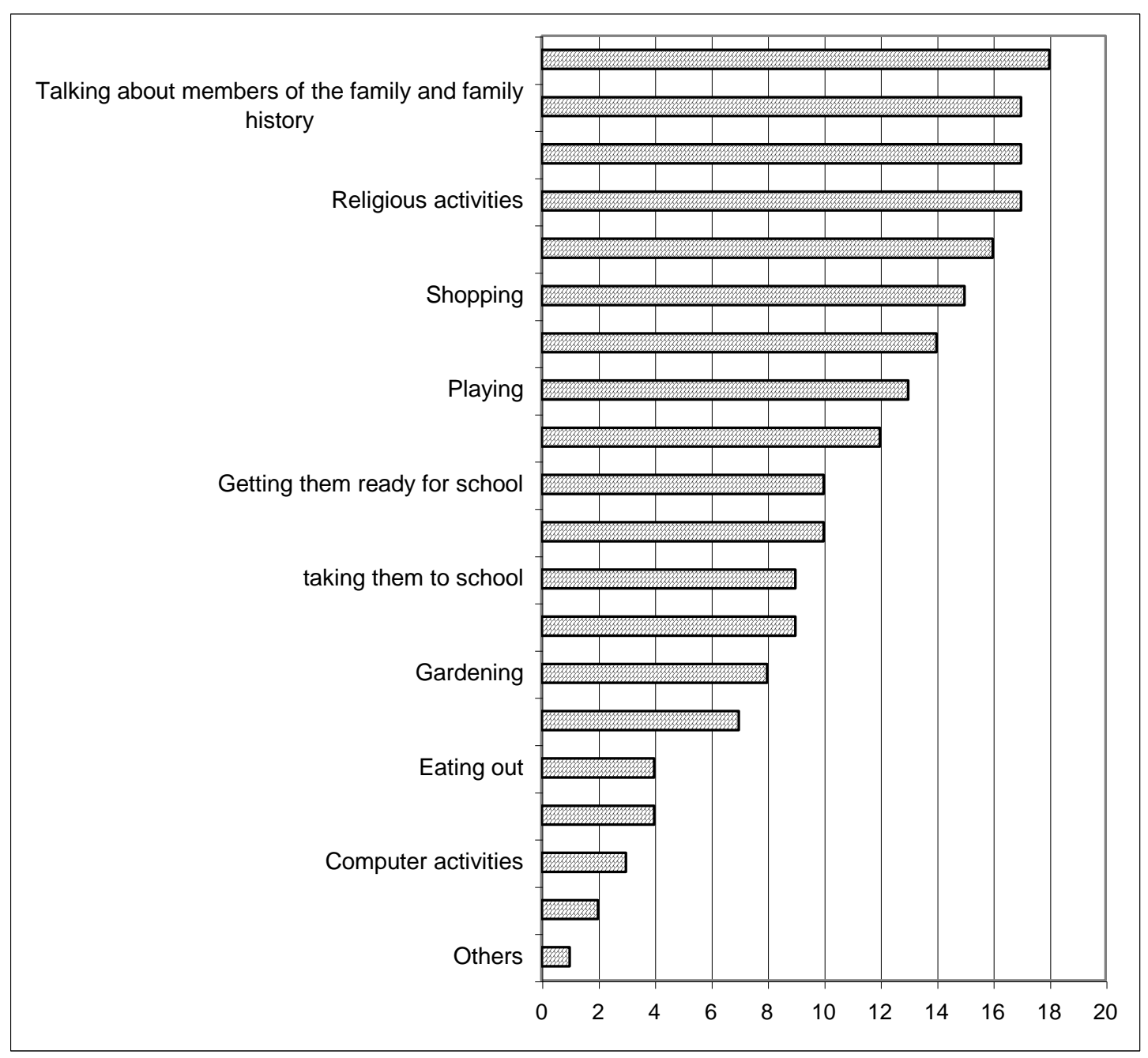

Figure 1: Number of grandchildren who took part in each activity with their grandparents 
The chart demonstrates that grandparents from these 17 Sylheti/Bengali-speaking families and 3 monolingual English-speaking families engaged in a wide range of learning events with their grandchildren, including outings to the park, telling stories and reciting rhymes, playing and reading together, and involving the children in cooking and gardening. The families of Bangladeshi origin placed a high priority on 'visiting others' and 'talking about members of the family and family history'. These activities had been included in the questionnaire at the instigation of members of the research team, themselves Bengali-speaking, who explained the significance of family visits in Bangladeshi culture. When children go to see relatives, often accompanying their grandparents, they learn how to greet each person appropriately and how to behave within the social group. They gain knowledge of each relative's place in the complex kinship network and where they themselves fit in, giving them a sense of their own identity. Conversations with grandparents also enhance their understanding of family history. The questionnaire responses emphasised the importance of these wider aspects of learning, underpinning children's understanding of social relationships.

The wide range of activities discussed above was found to take place regardless of whether grandparents and grandchildren lived together or apart, and regardless of their frequency of contact. For example, a grandparent who saw their grandchild three or four times a week reported eighteen different activities, another who saw their grandchild twice a week reported ten, and another who only saw their grandchildren every few weeks reported thirteen. 
With regard to the languages used in intergenerational learning, Figure 2 shows that in Bangladeshi families, most grandparents stated they used only Bengali with grandchildren. Some also used English, or Arabic for religious activities including prayer and recitation of the Qur'an.

\begin{tabular}{|l|l|}
\hline Languages & Number of families using \\
\hline Bengali & 8 \\
\hline Bengali, English & 4 \\
\hline Bengali, Arabic & 4 \\
\hline Bengali, Arabic, English & 1 \\
\hline
\end{tabular}

Figure 2: Languages used by grandparents with grandchildren in Bangladeshi families

The questionnaire served as an initial exploratory device to ascertain what kind of activities children and grandparents from different backgrounds engaged in together. When focusing on case studies of individual children, we were then able to refer back to the questionnaire findings in order to see how representative their experiences were (see Jessel et al, 2004, for an example of this process).

\section{Analysis of ethnographic data}

Having obtained the above overview, we used the videodata together with the interview and scrapbook material to generate a detailed understanding of the intergenerational learning exchange. Videodata was transcribed to show different channels of communication: language, gaze, and touch/action.

Qualitative analysis was conducted to look for common themes and patterns in the data, in the following ways: 
- Learning interactions were examined to find out how participants built on each other's meanings through talk and non-verbal interaction

- An inventory was drawn up of different concepts and skills featuring in the discussions and activities shared by participants

In the discussion of findings below, exemplars have been chosen from our substantial body of case-study data in order to illustrate each point.

\section{A relationship of mutuality}

Our data demonstrated the significance of the grandparent-grandchild relationship in terms of the amount of time spent together and the importance attached to the relationship by both sides. The older and younger generations provided for each other's needs, thus establishing a relationship that we have characterised as one of 'mutuality'.

In most families, grandparents played a key role in caring for their grandchildren, since parents were occupied with the demands of large families and/or paid employment. For example, Steven's grandmother would cancel other appointments to look after him, and often collected him from school even though she had to catch two buses to do so. Sumayah's grandmother was the main babysitter for her grandchildren and passed on childcare knowledge to her daughter-in-law. Abida's mother was busy with a newborn baby, so Abida spent a great deal of time with her grandparents. 
Grandparents described the enjoyment they gained from interacting with grandchildren. Sumayah's grandmother noted the energy provided by the younger generation to the older - 'grandchildren keep the house alive'. Anayet's grandmother spoke of how 'they fill our hearts with love and belonging' and explained that she and her grandson contributed to each other's sense of well-being: 'he phones me and lifts my spirits - we help each other'. Whilst mutual enjoyment of the relationship was mentioned by grandparents from all cultural backgrounds, it seemed particularly important for those who had migrated to Britain with their families, and therefore had fewer social networks. One mother in a Bangladeshi family said 'My daughter does everything - from eating to sleeping - with my parents. She can't live without them and they can't live without her'.

According to grandparents and children, their interaction had a different quality from the parent-child relationship. Sumayah's grandmother commented that grandparents 'show a different sort of love', a key aspect being that children 'get a sense of security and comfort from us'. All the children in Bangladeshi families who lived with their grandparents often chose to sleep in their grandmother's room, which gave a particular closeness. Two children in particular, one in a Bengali-speaking family and one in an English-speaking family, treated grandparents as playmates; Abida role-played being teacher with her grandparents as pupils, whilst the grandmother of Oscar and Cosmo said that her grandsons 'tend to think I'm like a big four-year-old'. Grandparents tended to show more indulgence; Steven rushed to investigate his grandmother's handbag as soon as he saw her, knowing that it would contain a little bag of biscuits for him since 'my Granny gives me what Mummy doesn't', and Sumayah said 'they buy us presents; they call it 'surprise present'.' 
Another factor in the relationship was children's recognition that the difference between youth and age sometimes gave them an advantage. Comparing his own hands to those of his grandmother, three-year-old Sam declared 'I'm not getting old...I've not got old skin'. The ageing process meant that grandparents might need their grandchildren's care. When Steven's grandmother came off the slide in the park awkwardly and hurt her head, Steven was distressed that he had insisted on her joining him in the activity and realised that 'Granny was getting too old for these things'. Sumayah recounted that 'when dada (grandpa) was ill we were very sad, we asked him what's wrong with his eyes'. Children responded protectively; Steven's grandmother said: 'He's always holding my hand when we go out, he thinks I'm going to get lost'.

The mutual vulnerability of the grandparent-grandchild relationship, combined with a sense of freedom and playfulness, meant that interactions operated on a relatively equal basis. We now examine how this context affected the process of intergenerational learning.

\section{Equal partners in learning}

We found that intergenerational learning interactions showed the following characteristics:

- Grandparents and children treated each other as equal partners in learning 
- Support from grandparents made the child an expert in tasks s/he could not accomplish alone, and children also supported grandparents' learning, particularly in the use of English and in tasks involving ICT

- Joint participation was constructed by an interplay between the communicative modes of language, touch, gesture and gaze

To exemplify these characteristics, we present an analysis of three extracts from video-recorded learning events. The first involves five-year-old Anayet typing his name in English on the computer, helped by his grandmother Mayarun. The second extract is from a cooking activity in which six-year-old Steven and his grandmother Gloria made fairy cakes together. In the third, six-year-old Sahil shows his grandmother Razia how to play the computer game 'Solitaire'. In each case, the beginning of the extract is included to show the transcription of different channels of communication: language, gaze, and touch/action. This kind of transcription builds on the work of Kress et al (2001) and Lancaster (2003) in using a multimodal approach to investigate learning interactions.

\section{Anayet and his grandmother Mayarun using the computer}

Anayet is at his grandmother's house, using the laptop provided by the research project. His grandmother, Mayarun, is sitting beside him with Anayet's toddler cousin on her lap. Anayet's aunt is nearby. The researcher has shown Anayet how to use the inbuilt mouse and he has started to press various keys, with his grandmother nodding and quietly saying the letters. During the activity, they code-switch between Sylheti and English, since Mayarun is also a confident English speaker. 
Sylheti is represented in italics, with English translation in brackets.

The Sylheti word nanu means 'granny' but can also be used affectionately to address the grandchild.

\begin{tabular}{|c|c|c|c|c|}
\hline Mayarun (M) & $\begin{array}{l}\text { Anayet } \\
\text { (A) }\end{array}$ & Aunt (Au) & Gaze & Touch / Action \\
\hline $\begin{array}{l}\text { tomar name } \\
\text { lekhta pharo ni? } \\
\text { nanu lekho sain } \\
\text { (can you write } \\
\text { your name? nanu } \\
\text { write then) }\end{array}$ & yes & & M looks at A & $\begin{array}{l}\text { A swaps hand } \\
\text { on keyboard to } \\
\text { left hand } \\
\text { A nods }\end{array}$ \\
\hline & & spell it out as well & & \\
\hline $\begin{array}{l}\text { khonta first } \\
\text { (what's first) } \\
\text { which one tomi } \\
\text { nanure khou sain } \\
\text { (which one you } \\
\text { tell nanu) } \\
\text { tomar first which } \\
\text { one, tomar nam } \\
\text { (your first which } \\
\text { one, your name) }\end{array}$ & & & $\begin{array}{l}\text { M looks at A } \\
\text { A looking at } \\
\text { screen } \\
\text { M looks to } \\
\text { and fro from } \\
\text { A to keyboard }\end{array}$ & $\begin{array}{l}\text { M points at } \\
\text { keyboard with } \\
\text { her index finger } \\
\text { A holds his } \\
\text { bottom lip with } \\
\text { LH fingers and } \\
\text { looks at screen } \\
\text { intently } \\
\text { M points to } \\
\text { letter 'A' and to } \\
\text { general area of } \\
\text { keyboard }\end{array}$ \\
\hline & eou & & $\begin{array}{l}\text { A focuses } \\
\text { gaze on same } \\
\text { area of } \\
\text { keyboard }\end{array}$ & $\begin{array}{l}\text { A nods his } \\
\text { head }\end{array}$ \\
\hline which one? & & $\begin{array}{l}\text { which letter? } \\
\text { which letter } \\
\text { ota ni? (is it that } \\
\text { one?) }\end{array}$ & M looks at A & $\begin{array}{l}\text { M points at } \\
\text { keyboard near } \\
\text { letter 'A' } \\
\text { A points with } \\
\text { his RH index } \\
\text { finger to letter } \\
\text { A }\end{array}$ \\
\hline
\end{tabular}


Mayarun suggests Anayet writes his name. She reinforces this suggestion through gaze, looking at him directly. Anayet nods in agreement. Asking 'khonta first?' (what's first?), Mayarun points at the keyboard and then to the letter 'A' to encourage him to begin. However, she does not press any key herself. Anayet's aunt joins in, also switching between English and Sylheti.

The episode continues (transcript not shown from this point). Anayet decides that the first letter needed is ' $\mathrm{N}$ '. His grandmother checks 'firste $\mathrm{N} n i$ ?' (is it $\mathrm{N}$ first?), using gaze to emphasise her query and pointing at ' $\mathrm{A}$ ' again. Gradually, Anayet moves to press 'A' and is rewarded with 'good' from Mayarun. She asks for the next letter and Anayet says ' $\mathrm{Y}$ ', pointing at it.

Mayarun questions this 'A...N aibo naini?' (A...N next isn't it?) and Anayet returns to 'N'. He then decides to look for ' $\mathrm{Y}$ ' and his grandmother supports him verbally 'Y tomi bair khoro sai?' (Y - can you find it?) and by moving her finger around the keyboard to participate in the search. Anayet's smile as he presses the letter is mirrored by an answering smile from his grandmother, as he exclaims 'Oh!' in satisfaction.

Anayet continues to take the lead, refusing his grandmother's offer to press the ' $E$ ' key. Finally she sounds out his entire name to remind him of the last letter, ' $\mathrm{T}$ '. Anayet presses this letter with a smile and his accomplishment is confirmed by his grandmother saying ' $\mathrm{T}$ ' and his own remark ' $\mathrm{T}$ - shesh' ( $\mathrm{T}$ - finished). 
This subtle and sensitive support develops Anayet's ability to spell his name, using the keyboard as a tool. Mayarun code-switches into English to highlight concepts used ('name', 'letter') and to signal the sequence of events ('first', 'which one').

\section{Steven and his grandmother Gloria cooking}

Steven is at his grandmother Gloria's house, standing on a stool in front of the sink in her kitchen, so that he can reach the worktop. Gloria is standing next to him and together they are stirring a batter to make fairy cakes. The transcript extract is part of a cookery session lasting almost an hour, during which they also make bread sticks.

\begin{tabular}{|l|l|l|l|}
\hline Gloria (G) & Steven (S) & Gaze & Touch/action \\
\hline put it in & ohhh! & Both looking at bowl & $\begin{array}{l}\text { S holding wooden spoon } \\
\text { in right hand and G lifting } \\
\text { metal spoon out of bowl }\end{array}$ \\
\hline $\begin{array}{l}\text { ohhh! } \\
\text { in an } \\
\text { answering } \\
\text { intonation) }\end{array}$ & & & $\begin{array}{l}\text { S brings left hand and } \\
\text { holds wooden spoon with } \\
\text { both hands and stirs, shifts } \\
\text { spoon to left hand and stirs } \\
\text { with left hand only }\end{array}$ \\
\hline & & $\begin{array}{l}\text { S holds bowl with right } \\
\text { hand while stirring with } \\
\text { left hand and bends } \\
\text { towards bowl. } \\
\text { G turns towards S }\end{array}$ \\
\hline & & $\begin{array}{l}\text { G gaze on tin in left hand } \\
\text { S gaze on bowl }\end{array}$ & S lets go of bowl \\
\hline
\end{tabular}

The multimodal transcript highlights the complexity of action taking place, with relatively little verbal input. Steven is learning how to control and manipulate the wooden spoon in stirring, sometimes using his right hand and sometimes his left, or both together. The only talk is Gloria's comment 'put it in' and Stephen's 'ohhh!' as an ingredient is added, followed by Gloria's answering 'ohhh!' which reinforces their joint enjoyment of the activity. Their gaze is on the tools being used to accomplish the 
task. At a later point Gloria's gaze turns to Steven and he makes a remark about the consistency of the batter ('it's sticky'), which she acknowledges with 'yes'.

Gloria then places her hand below her grandson's on the spoon handle whilst verbally signalling why: 'you put the flour in now and let granny stir it'. Steven puts in an unexpectedly large amount of flour but Gloria only comments 'oh...there's lots'. She indicates his turn to stir again, by making the offer verbally and by letting go of the spoon and mixing bowl. Meanwhile she takes over the tricky task of putting in the rest of the flour.

When the batter becomes too stiff for Steven to stir alone, Gloria offers to help, placing her hand on the spoon too. Grandmother and grandson stir together, Gloria's hand between both of Steven's. Although Steven maintains 'I can do it' and 'it's not stiff', he allows Gloria to continue. She gently persuades him to accept her aid: 'let granny help you...right'.

Steven receives adult supervision throughout this event, and is given responsibility and treated as a successful participant. Rather than using verbal criticism, Gloria takes supportive action to remedy any difficulty. Joint activity is embedded in a relationship of mutual warmth and trust, giving a relaxed tempo in which Steven can find his own rhythm.

\section{Sahil and his grandmother Razia playing 'Solitaire' on the computer}

Sahil and his two younger sisters are at home with their grandmother Razia, who lives in the same house. They have been doing a number of activities together on this 
particular day, including making bead necklaces, handwriting and story reading in

Bengali. Now Sahil has set up the card game 'Solitaire' on the computer and is

showing his grandmother how to play it.

\begin{tabular}{|c|c|c|c|}
\hline Razia $(\mathbf{R})$ & Sahil (S) & Gaze & Touch/action \\
\hline $\begin{array}{l}\text { dadu tho computer khelte } \\
\text { pari na tomi dekhai dou } \\
\text { (Granny does not know } \\
\text { how to play computer, } \\
\text { you show me) }\end{array}$ & & $\begin{array}{l}\mathrm{S} \text { at screen } \\
\mathrm{R} \text { looks at } \mathrm{S}\end{array}$ & $\begin{array}{l}\mathrm{S} \text { is manipulating the mouse } \\
\text { and } \mathrm{R} \text { is standing beside him } \\
\text { leaning towards him with her } \\
\text { left hand on back of his chair }\end{array}$ \\
\hline \multirow[t]{3}{*}{ som } & $\begin{array}{l}\text { akhane akhane } \\
\text { (here here) }\end{array}$ & \multirow[t]{4}{*}{$\mathrm{R} / \mathrm{S}$ at screen } & \\
\hline & $\begin{array}{l}\text { ami jani...tomi koro } \\
\text { (I know...you do it) }\end{array}$ & & $\begin{array}{l}\text { R's hand hovers near mouse } \\
\text { S brings R's hand to mouse } \\
\text { and places his hand over hers }\end{array}$ \\
\hline & $\begin{array}{l}\text { darou ...ami } \\
\text { (wait...I) }\end{array}$ & & $\begin{array}{l}\text { S removes R's hand from } \\
\text { mouse and places his own } \\
\text { hand on mouse } \\
\mathrm{R} \text { tries to put her hand back on } \\
\mathrm{S} \text { 's hand but he stops her with } \\
\text { his other hand }\end{array}$ \\
\hline \multirow[t]{2}{*}{$\begin{array}{l}\text { dou ami } \\
\text { (give me) }\end{array}$} & & & $\begin{array}{l}\mathrm{R} \text { assertively puts her hand } \\
\text { back on mouse, } \mathrm{S} \text { moves his } \\
\text { hand away }\end{array}$ \\
\hline & $\begin{array}{l}\text { akhon koro } \\
\text { (do it now) } \\
\text { na akhane...akhon koro } \\
\text { (no here, now do it) }\end{array}$ & $\mathrm{R} / \mathrm{S}$ at screen & $\begin{array}{l}\text { S puts his hand back on R's } \\
\text { hand and moves her hand away } \\
\text { S gives the mouse to R and } \\
\text { places his hand back on R's }\end{array}$ \\
\hline hmm & $\begin{array}{l}\text { aita kothai rakhbe...darou } \\
\text { (where will you put this } \\
\text { one... wait) } \\
\text { aita...heh akhane rakhte } \\
\text { parbe na } \\
\text { (this one...eh you can't put } \\
\text { it here) }\end{array}$ & & $\begin{array}{l}\text { S removes R's hand and shows } \\
\mathrm{R} \text { using his hand on the mouse } \\
\text { how to drag and drop the cards } \\
\text { where they should go }\end{array}$ \\
\hline
\end{tabular}

Whereas Razia had taken the lead in the previous activities of necklace-making and

Bengali story reading and handwriting, the lead switches to her grandson once the 
computer is involved. Razia knows card games that she used to play in a group in Bangladesh, but is unfamiliar with 'Solitaire' and with the computer itself. Sahil shows her how the game works by moving cards to particular places on the screen. He offers his grandmother a turn: 'I know... you do it', placing his hand over hers to help her guide the mouse and indicating that she should click the left mouse button.

An interplay between their hands ensues as Sahil decides to take charge of the mouse again and Razia tries to take it back. Eventually Sahil returns the mouse to his grandmother, before taking possession of it once more in order to demonstrate how to drag and drop the cards. At the same time, his verbal commentary highlights the position where this particular card can be placed in order to play the game correctly.

Sahil plays an expert role here, speaking with confidence to give his grandmother instructions in Bengali, and passing on the skills he has learnt in operating the computer as well as the rules of the card game. Razia is keen to join in but defers at key moments to her grandson's greater knowledge and dexterity. The overall learning relationship is a balanced one in which both partners remain actively involved.

\section{Touch as a communicative mode}

A multimodal transcription of our videodata highlighted the role of touch as a particularly significant means of communication, used by grandparents and grandchildren to build a secure and confident relationship and to negotiate kinaesthetic learning.

We identified the following purposes for which touch was used: 
- Confirming the grandparent/child relationship

- Constructing the event

- Guiding

- Shadowing

- Enabling

- Disciplining

\section{Confirming the grandparent/child relationship}

The videodata emphasises the physical closeness between the older and younger generation. For example, Sahil and his grandmother interlaced their fingers after they had been reading Bengali poetry together. Lizzie rubbed her cheek on her grandmother's arm as they looked at a webpage on the internet. This is a flexible form of touch used for reassurance by both generations, which flows into physical guidance as described below.

\section{Constructing the event}

Adults and children used touch to organise aspects of their joint activity. For example, Sam's grandmother held him more firmly as he became tired during a computer game, encircling him with her arms and patting his stomach to maintain his concentration. Anayah's grandmother pointed and tapped letters needed for making up words in a jigsaw game, and ran her finger along the whole word when it was completed. Meanwhile, Anayah placed her hand on her grandmother's arm to stop her breaking up the puzzle. 


\section{Guiding}

Grandparents often placed a hand over their grandchild's in order to physically demonstrate an action, and children sometimes guided their grandparents in a similar way. This was a negotiated form of touch that ebbed and flowed according to the need gauged by the participants. Sahil's grandmother guided his hand as he wrote in Bengali, enabling him to experience the flow of the pen on the page to inscribe the pattern of each letter. He pushed her hand away when he was writing a letter he felt confident with, and also when he changed to writing in English. A few moments later, the 'Solitaire' game discussed above took place, and Sahil placed his hand on top of his grandmother's to guide her in moving the mouse for the computer.

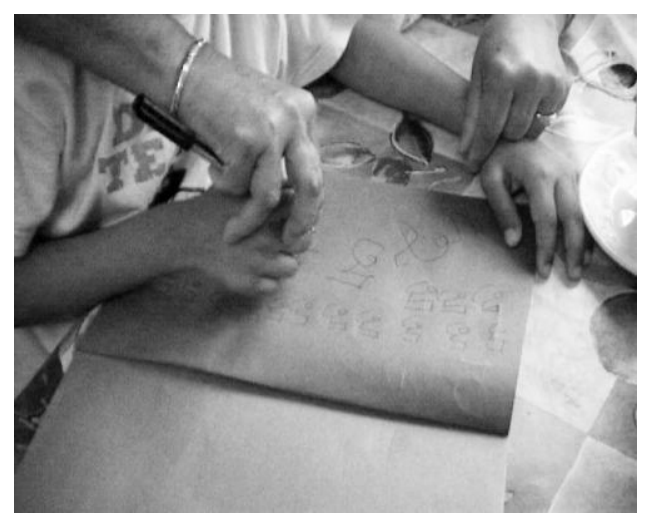

Figure 3: Sahil's grandmother guides his hand.

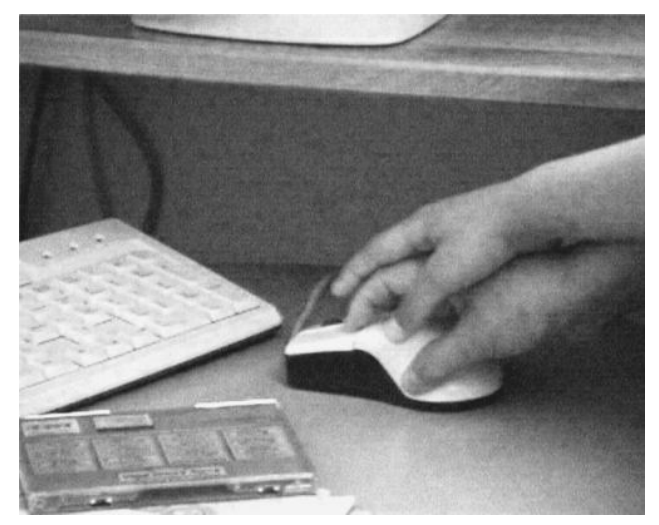

Figure 4: Sahil guides his grandmother's hand. 


\section{Shadowing}

Grandparents would 'shadow' children's actions with their hands poised alongside the child's, ready to guide when necessary. Abida's grandfather moved his hand in synchrony with his grand-daughter's, just alongside her as she pressed keys on the computer keyboard. Whilst Steven practised breaking eggs into the mixing bowl, his grandmother's hand hovered next to his.

\section{Enabling}

Physical help was sometimes needed by children to accomplish a task. Lizzie's grandmother lifted her up when the copier was out of reach. Steven's grandmother helped him to stir dough when it became too stiff for him to do alone. When grandchildren perceived their grandparents as frail, enabling could go the other way; Oscar helped his grandmother to the top of the slide because she was terrified of heights, and showed her how to position herself for the descent, saying 'big people go down like this'.

\section{Disciplining}

Grandparents tended to use touch rather than talk to re-orient children's behaviour. When Sam began to dig a pencil point into the mousemat, his grandmother moved his hand away gently and replaced the pencil on one side of the desk. When Steven wanted to use the guillotine to cut paper in a classroom, his grandmother put her hands around his waist and moved him away from the table, without verbal comment.

\section{Concepts and skills developed in intergenerational learning}


The intergenerational knowledge exchange observed in our case studies

complemented children's school learning and contributed to lifelong learning for grandparents. The chart in Figure 3 identifies concepts and skills being developed through each learning activity.

\begin{tabular}{|c|c|c|}
\hline Activity & Concepts & Skills \\
\hline $\begin{array}{l}\text { Storyreading and } \\
\text { storytelling }\end{array}$ & $\begin{array}{l}\text { Story structure } \\
\text { Developing imaginative } \\
\text { response } \\
\text { Vocabulary and syntax in } \\
\text { English or Bengali }\end{array}$ & $\begin{array}{l}\text { Bibliographic knowledge: } \\
\text { title, directionality of book }\end{array}$ \\
\hline Reciting Bengali poetry & $\begin{array}{l}\text { Rhyme } \\
\text { Literary language } \\
\text { Cultural understanding eg } \\
\text { respect for elders - } \\
\text { through subject matter of } \\
\text { poems }\end{array}$ & $\begin{array}{l}\text { Memorising } \\
\text { Reciting with cadence and } \\
\text { rhythm } \\
\text { Accurate pronunciation }\end{array}$ \\
\hline $\begin{array}{l}\text { Writing in Bengali and } \\
\text { English }\end{array}$ & $\begin{array}{l}\text { How different writing } \\
\text { systems operate }\end{array}$ & $\begin{array}{l}\text { Kinaesthetic skills of } \\
\text { handwriting in different } \\
\text { scripts }\end{array}$ \\
\hline $\begin{array}{l}\text { Playing word jigsaw game } \\
\text { in English }\end{array}$ & $\begin{array}{l}\text { Sound-symbol } \\
\text { relationships } \\
\text { Spelling: letter } \\
\text { combinations and order }\end{array}$ & $\begin{array}{l}\text { Familiarity with letter } \\
\text { shapes and sounds }\end{array}$ \\
\hline $\begin{array}{l}\text { Writing name in English } \\
\text { on computer }\end{array}$ & $\begin{array}{l}\text { Sound-symbol } \\
\text { relationships, spelling }\end{array}$ & Word processing skills \\
\hline Reading the Qur'an & $\begin{array}{l}\text { Appropriate preparation } \\
\text { for religious ritual (change } \\
\text { clothes, wash, spread out } \\
\text { prayer mat) } \\
\text { Religious values } \\
\text { Literary language: } \\
\text { classical Arabic }\end{array}$ & $\begin{array}{l}\text { Memorising } \\
\text { Recitation } \\
\text { Intonation }\end{array}$ \\
\hline $\begin{array}{l}\text { Playing games on } \\
\text { computer }\end{array}$ & $\begin{array}{l}\text { Topic information (eg } \\
\text { types of transport) } \\
\text { Literacy and numeracy } \\
\text { Ordering and categorising }\end{array}$ & $\begin{array}{l}\text { Hand-eye co-ordination: } \\
\text { manipulating mouse } \\
\text { Fine motor control: } \\
\text { clicking mouse }\end{array}$ \\
\hline
\end{tabular}




\begin{tabular}{|c|c|c|}
\hline & (eg Solitaire card game) & \\
\hline $\begin{array}{l}\text { Looking up information } \\
\text { via internet }\end{array}$ & $\begin{array}{l}\text { Topic information (eg } \\
\text { types of moth) } \\
\text { Intertextual links (compare } \\
\text { to information found in } \\
\text { books) } \\
\text { Connections between } \\
\text { categories (conducting } \\
\text { searches) }\end{array}$ & $\begin{array}{l}\text { Techniques of word } \\
\text { processing } \\
\text { Navigating around } \\
\text { hypertext }\end{array}$ \\
\hline Cooking & $\begin{array}{l}\text { Finding way round recipe } \\
\text { book - recognising } \\
\text { appropriate section } \\
\text { Ingredients that make up a } \\
\text { recipe } \\
\text { Weighing and measuring } \\
\text { Texture and consistency of } \\
\text { different materials }\end{array}$ & $\begin{array}{l}\text { Knowing names and } \\
\text { functions of kitchen } \\
\text { implements } \\
\text { Techniques involving fine } \\
\text { motor control: chopping, } \\
\text { stirring, rolling and } \\
\text { plaiting dough, cracking } \\
\text { eggs }\end{array}$ \\
\hline Gardening & $\begin{array}{l}\text { Conditions of plant } \\
\text { growth: different amounts } \\
\text { of light and water needed } \\
\text { Classifying plants } \\
\text { Cultural knowledge about } \\
\text { fruit and vegetables grown } \\
\text { in different countries } \\
\text { Vocabulary for fruit and } \\
\text { vegetables in English and } \\
\text { Bengali }\end{array}$ & $\begin{array}{l}\text { Motor control: tipping } \\
\text { watering-can at different } \\
\text { angles, pushing broom to } \\
\text { sweep up }\end{array}$ \\
\hline $\begin{array}{l}\text { Playing sports and } \\
\text { physical games }\end{array}$ & Rules of games & $\begin{array}{l}\text { Developing fitness, } \\
\text { suppleness and hand-eye } \\
\text { co-ordination }\end{array}$ \\
\hline $\begin{array}{l}\text { Talking about family and } \\
\text { family history }\end{array}$ & $\begin{array}{l}\text { Kinship relationships } \\
\text { Understanding historical } \\
\text { time } \\
\text { Sense of own history and } \\
\text { identity }\end{array}$ & $\begin{array}{l}\text { Appropriate greetings for } \\
\text { people of different ages / } \\
\text { relationships }\end{array}$ \\
\hline Visiting others & $\begin{array}{l}\text { Understanding social } \\
\text { networks }\end{array}$ & $\begin{array}{l}\text { Appropriate behaviour in a } \\
\text { social group }\end{array}$ \\
\hline
\end{tabular}

Figure 5: Concepts and skills developed in intergenerational learning events 
The activities listed at the beginning of the table would be commonly recognised by schools as supporting literacy learning. In families of Bangladeshi origin, children were developing understandings of rhyme, story construction, vocabulary and writing systems in more than one language. Research on bilingualism (Baker, 2006) shows that such experience enhances metalinguistic knowledge as children compare how different languages operate. Concepts formulated in one language can be transferred to the other. We have discussed elsewhere how Sahil's literacy learning, for example, was supported by reciting Bengali poetry and writing in Bengali with his grandmother (Jessel et al, 2004).

Activities such as cookery and gardening involved situated and authentic learning that also aided the development of curriculum-related concepts and skills. We have conducted a detailed examination of gardening as a source of early scientific knowledge elsewhere (Ruby et al, forthcoming). A broader definition of learning, going beyond curriculum targets, is required to encompass the rich variety of knowledge children gain from spending time in family settings. As mentioned earlier, activities such as talking about family and family history, along with visiting others, are not always recognised as significant in the school curriculum. Yet the resulting formation of a sense of identity and the development of social skills make a key contribution to citizenship. The way in which intergenerational activities complemented children's learning at school was highlighted by Anayet's grandmother when she said 'the work we do at home, the time we spend together is so important, it's extra'. 
The chart includes new learning and the maintenance of skills for the older generation. As Steven's grandfather said of playing football with him: 'Having the grandchildren around keeps you healthy and fit...you run after the ball together...you fall but you get up and go again'. Sahil's grandmother stated that her grandchildren 'introduce me to new things and new ways'. Lizzie and Sam's grandmother felt they helped her to keep 'a fresh and open mind', and hoped Lizzie would teach her about word processing. Several Bangladeshi grandparents mentioned learning English through interactions with grandchildren. Anayah's grandmother said 'she compliments me when I speak English', whilst Anayet corrected his grandmother's pronunciation. Sumayah related how she and her siblings helped their grandparents in this respect: 'we teach them English, but my Dada [grandpa] already knows it, they don't know how to spell 'mum', we say to them 'M...U...M'. Anayet's grandmother explicitly commented on the two-way nature of the interaction: 'we learn from each other'.

\section{Combining knowledge}

The older and younger generations used their different capabilities to create shared understandings, leading to new forms of linguistic and cultural learning. This could occur around a text that was itself a cultural blend, such as Sahil's 'Snow White' storybook produced in Bangladesh, as we have discussed elsewhere (Gregory et al, 2007). The book's illustrations showed both Western and Asian aspects, whilst the storyline referred to moral virtues admired in Bangladeshi culture. Sahil's grandmother read the book with her grandchildren, giving them access to the text in Bengali. When the dwarves appeared in the story with the Bengali translation 'little men', Sahil explained the fuller meaning in Bengali from his knowledge of the English version. 
When Sumayah worked in the garden with her grandparents, she combined learning gained from interactions in Sylheti with the conceptual knowledge she was simultaneously building up in English (Ruby et al, forthcoming). Videorecorded in the garden, Sumayah identified fruit and vegetables such as different types of pumpkin in Sylheti/Bengali, and pointed out the new leaves on a lemon tree to her grandmother. She also described the size and colour of apples on the trees in English when addressed in English by her mother.

\section{Passing on knowledge of family history, language and culture}

Grandparents had a sense of maintaining continuity for a new generation by passing on their experience of family history. Sam's grandmother brought family experiences into a computer game on the history of transport which she was playing with Sam, pointing out that she or his uncle had been born in the era when particular kinds of plane first appeared. Sumayah's grandmother commented 'we pass on a lot to them... we tell them stories of Bangladesh, how we live there, what we grow, what we eat, how we do things... things have changed a lot, we tell them stories of times that have gone, about our lives, the way we were brought up'. Such information was particularly important to build links for children with their families' country of origin.

The Bangladeshi grandparents were a key resource for developing children's knowledge of Bengali, thus retaining a connection with heritage and culture. Sahil's grandmother spent time reciting Bengali poetry with her grandchildren and reading them books brought by her daughter-in-law from Bangladesh. Many Bengali-speaking 
grandparents introduced grandchildren to Arabic for the purposes of reading the Qur'an: 'Anayet loves to watch me and copy me when I'm praying'.

\section{Continuity and change}

In some aspects, activities done with grandchildren emphasised the link between generations. Anayah's grandmother said she followed the ways and practices of her own grandparents: 'It comes to mind a lot'. Sahil's grandmother remembered putting henna on her daughter's hands, just as her daughter now does with Sahil's sisters, and Lizzie and Sam's grandmother remembered the enjoyment of looking through her grandmother's jewellery box, just as she herself now does with her own grandchildren. In other aspects, grandparents discerned a change in the grandparenting role between generations. Lizzie and Sam's grandmother noted that the 'action-packed visits' of her grandchildren contrasted with her memories of more formal interaction with her own grandmother in the 1940s, whilst Anayet's grandmother felt that 'the level of respect, love and obedience has changed from my time'.

The kinds of knowledge now considered important had changed: Oscar and Cosmo's grandmother pointed out that, for her grandsons, computer skills were 'like learning to read and write...the three R's, it's the fourth one'. Abida's grandfather said 'a lot of things have modernised and computerised, they have a lot more global knowledge than us'. However, Sahil's grandmother felt that 'in Bangladesh children learn so much more especially in the villages watching the animals and having hands-on experience'. She had spent a year in Bangladesh with Sahil and bought him a goat so he could benefit from this experiential learning. Like the other children in the study, 
Sahil continued to have access to the accumulated knowledge of past generations via his grandparents, whilst simultaneously developing new technological skills.

\section{Implications for sociocultural theory}

Our findings extend theories of sociocultural learning by highlighting the unique learning relationship of grandparents and grandchildren, to which each generation brings particular knowledge and skills.

\section{Scaffolding and synergy}

Whilst the grandparents in our study were providing 'scaffolding' in terms of cognitive support enabling children to accomplish a task they could not have done alone, intergenerational learning interactions were conducted in a context of mutuality and thus in a relatively equal way. 'Synergy' therefore seems a more appropriate term to describe the learning process between grandparents and grandchildren. A multimodal analysis of learning events has revealed how synergy is mediated through touch and gaze as well as verbally, with touch being used for a particularly wide range of communicative purposes.

Grandparents treated children as competent co-constructors of the event, giving them plenty of time to act and only offering guidance when this was evidently needed. At the same time, the warmth and closeness of the relationship reassured children that guidance was continually available. Meanwhile, children also provided support for adult learning, particularly when using the computer together. They expressed mutual care and sensitivity for their grandparents as learners. 


\section{Syncretism and funds of knowledge}

The study demonstrates how 'funds of knowledge' were held by both generations rather than by adults only. This was the case for both Bengali-speaking and Englishspeaking families with regard to children's knowledge of new technology, for example. The resources brought by children to the relationship were especially prominent in bilingual families, where grandparents often depended on the younger generation's understanding of English in order to accomplish an activity.

Syncretism emerges as a key characteristic of intergenerational learning activities. The dynamic creation of new cultural understandings as participants blended or 'syncretised' their respective knowledge was evident, for example when Sahil's grandmother brought her experience as a reader of Bengali literature to co-construct an interpretation of the European traditional tale 'Snow White' more familiar to her grandson.

\section{Prolepsis}

In the project findings we see that 'prolepsis', the handing down of experience from the older generation, now involves adaptation to the input of very young children. Grandparents from all cultural backgrounds recognised that the passing on of their experience had to be negotiated with the younger generation, and that knowledge and values would be re-evaluated in the context of a rapidly-changing world where their grandchildren often held the advantage. 


\section{Issues for further research}

This study was conducted with a small number of children from two main linguistic groups, Bengali-speaking and monolingual English-speaking, and the ideas arising could now be investigated with a larger sample from a wider range of linguistic backgrounds. A longitudinal study would also be of benefit, looking at how relationships change between children and grandparents across the age span. The role of parents within intergenerational relationships is another area of interest, and we are now embarking on research into the dynamics of interaction between three generations - children, parents and grandparents - and the effects on children's learning.

\section{Implications for educators}

The study suggests that schools need to be aware of the special relationship between children and grandparents and how this contributes to learning at home. Teachers can build links with grandparents by inviting them into school to share their knowledge and experience. Family learning sessions can involve grandparents as well as parents, and can include areas new to the older generation such as computer activities or English as a second language, thus facilitating lifelong learning. When involving grandparents in family learning initiatives, value must be given to their existing expertise.

As an example of how such links could be stimulated, our research began with a Grandparents' Coffee Morning held at the school, to set up a dialogue with grandparents about the important role they played in children's learning. The project ended with a Grandparents' Fair, held in the school computer suite where 
grandparents had an informal opportunity to try out the facilities with their grandchildren. The participating families attended together with teachers and with representatives of the local education authority and family learning organisations, to reflect on our findings and share ideas on intergenerational learning.

\section{Conclusion}

This study demonstrates that when young children and grandparents jointly participate in events ranging from storytelling to computer activities, the exchange of knowledge enhances learning for both generations. Whilst the detail of the intergenerational exchange differs according to each family's linguistic and cultural background, perhaps the most striking finding is that many aspects are similar: mutuality of the learning relationship; grandparents passing on knowledge of family history, language and culture; and children offering new knowledge to the older generation. In each case, learning with grandparents at home develops concepts and skills relevant to children's formal education, and this significant contribution needs to be recognised by schools.

\section{Acknowledgements}

Our thanks go to the families who participated in the research project, and to Hermitage Primary School.

This research was funded by the ESRC (Award R000220131). 


\section{*Note}

Sylheti is an oral language from the area of Sylhet in Bangladesh. This was the language spoken by most of the families in the study, with Standard Bengali being used in writing. Some families also spoke varieties of Bengali and thus we have adopted the term Sylheti/Bengali to cover the range of languages used.

\section{References}

Attias-Donfut, C. \& Segalen, M.(2002) 'The construction of grandparenthood'. Current Sociology 50(2): 281-294.

Baker, C. (2006) Foundations of Bilingual Education and Bilingualism (4 $4^{\text {th }}$ edition). Clevedon, Avon: Multilingual Matters.

Cairney, T. and Ruge, J. (1998) Community Literacy Practices and Schooling:

Towards Effective Support for Students. Canberra, DEET.

Cole, M. (1996) Cultural Psychology: A Once and Future Discipline. Cambridge, Mass: Harvard UP.

Cole, M. and Scribner, S. (1978) Introduction. In L. Vygotsky, Mind in Society. Cambridge, Mass: Harvard U.P. 
Clarke, L. and Cairns, H. (2001) 'Grandparents and the care of children: the research evidence'. In Broad, B. (ed) Kinship Care. Lyme Regis: Russell House Publishing.

Dench, G. and Ogg, J. (2002) Grandparenting in Britain: A Baseline Study. London: Institute of Community Studies.

Duran, P. (2001) 'How may children help their immigrant parents learn L2 English? : a focus on verb learning in homework interactions'. Paper presented at BAAL Annual Meeting, Reading, England.

González, N., Moll, L. and Amanti, C. (2005) Funds of Knowledge: Theorizing Practices in Households, Communities and Classrooms. Mahwah, New Jersey: Erlbaum.

Granville, G. \& Ellis, S. (1999) 'Developing theory into practice: researching intergenerational exchange. Education and Ageing 14 (3), 231-248.

Gregory, E. and Williams, A. (2000) City Literacies. London: Routledge.

Gregory, E. (2001) Sisters and brothers as language and literacy teachers: synergy between siblings playing and working together'. Journal of Early Childhood Literacy $1(3): 301-322$.

Gregory, E., Long, S. and Volk, D. (2004) 'Syncretic literacy studies: starting points'. In E. Gregory, S. Long and D. Volk (eds) Many Pathways to Literacy: Young 
Children Learning with Siblings, Grandparents, Peers and Communities. London: Routledge.

Gregory, E., Arju, T., Jessel, J., Kenner, C. and Ruby, M. (forthcoming) 'Snow White in different guises: interlingual and intercultural exchanges between grandparents and young children at home in East London'. Journal of Early Childhood Literacy.

Hannon, P. (1995) Literacy, Home and School. London: Falmer Press.

Heath, S.B. (1983) Ways with Words. Cambridge: Cambridge University Press.

Jessel, J., Arju, T., Gregory, E., Kenner, C. and Ruby, M. (2004) 'Children and their grandparents at home: a mutually supportive context for learning and linguistic development'. English Quarterly 36 (4): 16-23.

Kenner, C. (2005) 'Bilingual families as literacy eco-systems'. Early Years 25 (3): 283-298.

Kress, G. (1997) Before Writing: Rethinking the Paths to Literacy. London: Routledge.

Kress, G., Jewitt, C., Ogborn, J. and Tsatsarelis, C. (2001) Multimodal Teaching and Learning: The Rhetorics of the Science Classroom. London: Continuum Press. 
Lancaster, L. (2003) 'Beginning at the beginning: how a young child constructs time multi-modally'. In Jewitt, C. and Kress, G. (eds) Multimodal Literacy. New York: Peter Lang.

Maybin, J., Mercer, N. and Stierer, B. (1992) '"Scaffolding" learning in the classroom'. In Norman, K. (ed) Thinking Voices: The Work of the National Curriculum Project. London: Hodder and Stoughton for the National Curriculum Council.

McNaughton, S. (1995) The Patterns of Emergent Literacy. Oxford: Oxford University Press.

Moll, L., Amanti, C., Neff, D. and González, N. (1992) 'Funds of knowledge for teaching; using a qualitative approach to connect homes and classrooms'. Theory into Practice 31 (2): 132-141.

Newman, S., Ward, C.R., Smith, T.B., Wilson, J.O. \& McCrea, J.M. (1997) Intergenerational Programs: Past, Present and Future. Washington: Taylor \& Francis.

Pollard, A. with Filer, A. (1996) The Social World of Children's Learning. London: Cassell.

Rashid, N. and Gregory, E. (1997) 'Learning to read, reading to learn: the importance of siblings in the language development of young bilingual children'. In Gregory, E. 
(ed) One Child, Many Worlds: Early Learning in Multicultural Communities.

London: David Fulton.

Richards, A. (2001) Second Time Around: A Survey of Grandparents Raising their Grandchildren. London: Family Rights Group.

Rogoff, B. (1990) Apprenticeship in Thinking. New York: Oxford U.P.

Ruby, M., Kenner, C., Jessel, J., Gregory, E. and Arju, T. (forthcoming) 'Gardening with grandparents: an early engagement with the science curriculum'. Early Years.

Smith, P. and Drew, L. (2002) 'Grandparenthood'. In Bornstein, M. (ed) Handbook of Parenting, Vol. 3: Being and Becoming a Parent. Mahwah, N.J. and London:

Lawrence Erlbaum Associates.

Tharp, R. \& Gallimore, R. (1988) Rousing Minds to Life. Cambridge: Cambridge U.P.

Van, K. (2004) 'Intergenerational theory in society: building on the past, questions for the future'. Journal of Intergenerational Relationships 2 (3-4): 75-94.

Volk, D. with de Acosta, M. (2004) 'Mediating networks for literacy learning: the role of Puerto Rican siblings'. In Gregory, E., Long, S. and Volk, D. (eds) Many Pathways to Literacy: Young Children Learning with Siblings, Grandparents, Peers and Communities. London: RoutledgeFalmer. 
Vygotsky, L. (1978) Mind in Society. Cambridge, Mass: Harvard U.P.

Wood, D., Bruner, J. and Ross, G. (1976) 'The role of tutoring in problem solving'. Journal of Child Psychology 17: 89-100. 